\begin{tabular}{|l|l|l||}
\hline \multicolumn{2}{|c|}{ PublisherInfo } \\
\hline \hline PublisherName & $:$ & BioMed Central \\
\hline \hline PublisherLocation & $:$ & London \\
\hline \hline PublisherImprintName & $:$ & BioMed Central \\
\hline \hline
\end{tabular}

\title{
Exploring the alternatives
}

\begin{tabular}{|l|c|l||}
\hline \multicolumn{2}{|c|}{ ArticleInfo } \\
\hline \hline ArticleID & $:$ & 4848 \\
\hline \hline ArticleDOI & $:$ & $10.1186 /$ gb-spotlight-20030930-01 \\
\hline \hline ArticleCitationID & $:$ & spotlight-20030930-01 \\
\hline \hline ArticleSequenceNumber & $:$ & 200 \\
\hline \hline ArticleCategory & $:$ & Research news \\
\hline ArticleFirstPage & $:$ & 1 \\
\hline \hline ArticleLastPage & $:$ & 4 \\
\hline \hline & & RegistrationDate : 2003-9-30 \\
\hline ArticleHistory & $:$ & OnlineDate \\
\hline \hline ArticleCopyright & $:$ & BioMed Central Ltd2003-9-30 \\
\hline \hline ArticleGrants & $:$ & \\
\hline \hline ArticleContext & $:$ & 130594411 \\
\hline \hline
\end{tabular}


Researchers agree that recent findings about alternative splicing point toward the therapeutic applications that lie in its future. But the newest news about this ubiquitous mechanism for making many mRNAs from a single gene - more than 38,000 , in one extreme Drosophila example - is that it appears to be crucial not just for generating lots of proteins, but probably for controlling gene expression as well.

"I believe it will be possible to generate therapeutic interventions based on alternate splicing," Donald Rio, of the University of California at Berkeley, told us. It is now understood that many disease-causing mutations ultimately result in altered RNA splicing. These mutations occur not only in well defined intron-exon junctions, but also in protein-coding exonic splicing control elements, said Rio, the keynote speaker at Splicing 2003, a meeting held Tuesday (September 23) in Rockville, Md.

Practical medical applications are perhaps 20 years away, according to Fyodor Kondrashov, who investigates the evolution of alternative splicing at the National Center for Biotechnology Information. But he would not be surprised, he said, to see alternative splicing used in medical technology eventually. "Perhaps a new isoform B may be created to regulate isoform A that is overproduced," he forecast.

A number of researchers cite work by Luca Cartegni and Adrian Krainer, molecular biologists at Cold Spring Harbor Laboratory, as demonstrating the potential for treating human diseases by modulating alternative splicing. Cartegni and Krainer found a way to include a piece of RNA that has been skipped in the splicing process. The method was modeled on natural proteins that guide which segments are included when pre-mRNA gets cut up and the cell gathers the essential bits and pastes them together. One end of these guide proteins attaches to the pre-mRNA transcript. The other end recruits enzymes that cut and paste.

Krainer and Cartegni attached the recruiting portion of the guide protein to a synthetic molecule that can be programmed to bind to any piece of RNA according to its sequence. They call the method ESSENCE (Exon-Specific Splicing Enhancement by small Chimeric Effectors) and have used it in vitro to correct splicing defects in mutants of the BRCA1 breast cancer gene and the SMN2 gene for spinal muscular atrophy. "There are still many technical issues to work out with this approach, but it has tremendous potential for treating many human-diseases," Brenton R. Graveley, of the University of Connecticut Health Center, told us.

Paula Grabowski, Howard Hughes Medical Institute investigator at the University of Pittsburgh, cited a similar approach reported by L.A. Skordis and colleagues at Hammersmith Hospital in London. The UK researchers designed oligonucleotides that were complementary to a portion of the exon missing in the $S M N 2$ gene and that also contained a tail with sequences that enhance exon splicing. The designer molecule increased incorporation of the missing exon in patient fibroblasts. Grabowski called the work, "One of the most important advances this year in alternative splicing."

Instead of including missing exons, some researchers are finding ways to get rid of destructive ones, according to Lynne Maquat, who is at the School of Medicine and Dentistry at the University of Rochester. Each approach has potential for treating diseases in which alterations in pre-mRNA splicing could result in too little functional protein, she said. Maquat's example was work by Q.L Lu and 
colleagues, also at Hammersmith Hospital, who in August reported on a way of eliminating a mutated exon in vivo in a mouse model of Duchenne muscular dystrophy, producing a dystrophin that was partially functional. Treated mice made the protein at normal levels in large numbers of muscle fibers, the UK researchers wrote, and there was functional improvement of the treated muscle.

"The coolest thing" at Splicing 2003, according to Graveley, was the notion that alternative splicing is important for control of gene expression, implied by recent work from Christopher W.J. Smith and his colleagues at Cambridge University, and other investigators. Smith told the meeting that he and his colleagues have found an alternatively spliced exon in the PTB gene (a gene that probably figures in premRNA splicing) that contains a premature stop codon. Thus, it is degraded by the cell mechanism called nonsense-mediated decay (NMD). NMD has traditionally been seen as the cell's mechanism for getting rid of junk RNA generated from alleles containing nonsense codons or from aberrant-splicing.

"It turns out that although this isoform appears to be present at a low level, it is actually a rather abundant isoform if the NMD pathway is inactivated. This is part of an autoregulatory loop for the PTB gene," Graveley told us.

Smith emphasized that research in his lab and elsewhere suggests a central role for alternative splicing besides the conventional wisdom that it is a mechanism for generating 100,000-plus human proteins from only 30,000 human genes. A recent bioinformatic analysis from Steven Brenner's lab at the University of California, Berkeley, estimated that approximately $30 \%$ of alternatively spliced human mRNAs are destined for NMD and may never get translated into protein, Smith said. "By definition, this $30 \%$ must be a lower estimate because RNAs that are destined for degradation must be poorly represented in EST databases," he noted.

If an even larger number of genes undergo alternative splicing than previously thought, that may mean alternative splicing is crucial for quantitative control of gene expression, by generating RNAs headed to the trash heap and NMD. "This could be a very important but underappreciated role for alternative splicing," Smith pointed out. Maquat said studies in her lab also support that role. At the meeting, she described the selenoprotein mRNA for glutathione peroxidase 1, which harbors a codon that directs selenocysteine incorporation as well as some level of translation termination leading to NMD. She told us, "It is now evident that NMD is used by cells as a means to regulate 'proper' gene expression."

\section{References}


1. Lewis R: RNA calls the shots 2003, The Scientist, 17:29., [http://www.the-scientist.com/yr2003/feb/ research1_030224.html]

2. The Second Annual Symposium on Alternative RNA Splicing, Rockville, Md., September 23, 2003, [http://www.exonhit.com/splicing2003/]

3. Weitzman J: The ESSENCE of exon inclusion 2003, Genome Biology., [http://genomebiology.com/ researchnews/default.asp?arx_id=gb-spotlight-20030117-01]

4. Bifunctional antisense oligonucleotides provide a trans-acting splicing enhancer that stimulates SMN2 gene expression in patient fibroblasts

5. Functional amounts of dystrophin produced by skipping the mutated exon in the mdx dystrophic mouse

6. Fogarty M: Researchers find a eukaryotic mRNA policing system The Scientist 2002, 16:26., [http://www.the-scientist.com/yr2002/apr/research2_020429.html]

7. Evidence for the widespread coupling of alternative splicing and nonsense-mediated mRNA decay in humans

This PDF file was created after publication. 